\title{
Operational Improvements from the In-Trail Procedure in the North Atlantic Organized Track System
}

\author{
Ryan C. Chartrand ${ }^{1}$ \\ NASA Langley Research Center, Hampton, Virginia, 23681 \\ Frank J.L. Bussink. ${ }^{2}$ and Thomas J. Graff ${ }^{3}$ \\ National Institute of Aerospace, Hampton, Virginia, 23681 \\ and \\ Jennifer L. Murdoch ${ }^{4}$ and Kenneth M. Jones ${ }^{5}$ \\ NASA Langley Research Center, Hampton, Virginia, 23681
}

\begin{abstract}
This paper explains the computerized batch processing experiment examining the operational impacts of the introduction of Automatic Dependent Surveillance-Broadcast (ADS-B) equipment and the In-Trail Procedure (ITP) to the North Atlantic Organized Track System (NATOTS). This experiment was conducted using the Traffic Manager (TMX), a desktop simulation capable of simulating airspace environments and aircraft operations. ADS-B equipment can enable the use of new ground and airborne procedures, such as the ITP. The ITP is among the first of these new procedures, which will make use of improved situation awareness in the local surrounding airspace of ADS-B equipped aircraft to enable more efficient oceanic flight level changes. The data collected were analyzed with respect to multiple operationally relevant parameters including fuel burn, request approval rates, and the distribution of fuel savings. This experiment showed that through the use of ADS-B or ADS-B and the ITP that operational improvements and benefits could be achieved.
\end{abstract}

\begin{tabular}{ll} 
& \multicolumn{1}{c}{ Nomenclature } \\
ADS-B & $=$ Automatic Dependent Surveillance-Broadcast \\
ADS-B IN & $=$ Automatic Dependent Surveillance-Broadcast (receive) \\
ADS-B OUT & $=$ Automatic Dependent Surveillance-Broadcast (transmit) \\
ASAS & $=$ Airborne Separation Assistance System \\
ATC & $=$ Air Traffic Control \\
ATM & $=$ Air Traffic Management \\
ATOL & $=$ Airspace and Traffic Operations Laboratory \\
ATSP & $=$ Air Traffic Service Provider \\
BADA & $=$ Base of Aircraft Data \\
CDTI & $=$ Cockpit Display of Traffic Information \\
CPDLC & $=$ Controller Pilot Data-Link Communication \\
FMS & $=$ Flight Management System \\
GFS & $=$ Global Forecast System \\
ICAO & $=$ International Civil Aviation Organization \\
ITP & $=$ In-Trail Procedure
\end{tabular}

${ }^{1}$ Research Aerospace Engineer, Crew Systems and Aviation Operations Branch, MS 156A, member AIAA.

${ }^{2}$ Research Engineer, Crew Systems and Aviation Operations Branch, MS 156A.

${ }^{3}$ Senior Airline Operations Expert, Crew Systems and Aviation Operations Branch, MS 156A.

${ }_{5}^{4}$ Senior Research Psychologist, Crew Systems and Aviation Operations Branch, MS 156A.

${ }^{5}$ Senior Research Engineer, Crew Systems and Aviation Operations Branch, MS 156A, Senior Member AIAA. 1

American Institute of Aeronautics and Astronautics 092407 


$\begin{array}{ll}\text { Kts } & =\text { Knots } \\ \text { LaRC } & =\text { Langley Research Center } \\ \text { MHz } & =\text { Mega-Hertz (frequency) } \\ \text { NASA } & =\text { National Aeronautics and Space Administration } \\ \text { NATOTS } & =\text { North Atlantic Organized Track System } \\ \text { NLR } & =\text { National Aerospace Laboratory (Netherlands) } \\ \text { nmi } & =\text { nautical miles } \\ \text { NOAA } & =\text { National Oceanic and Atmospheric Administration } \\ \text { NOTAM } & =\text { Notice to Airmen } \\ \text { OCA } & =\text { Oceanic Control Area } \\ \text { RADAR } & =\text { Radio Detection And Ranging } \\ \text { RFG } & =\text { Requirements Focus Group } \\ \text { RM0 } & =\text { Request method zero (requested altitude is the optimum altitude at entry) } \\ \text { RM1 } & =\text { Request method one (optimum at entry plus } 1000 \text { feet-compromise altitude) } \\ \text { SA } & =\text { Situation Awareness } \\ \text { SASP } & =\text { Separation and Airspace Safety Panel } \\ \text { SPR } & =\text { Safety, Performance and Interoperability Requirements } \\ \text { TCAS } & =\text { Traffic alert and Collision Avoidance System } \\ \text { TDA } & =\text { Traffic Density Analyzer } \\ \text { TIS-B } & =\text { Traffic Information Services - Broadcast } \\ \text { TMX } & =\text { Traffic Manager } \\ \text { U } & =\text { NATOTS track } \\ \text { V } & =\text { NATOTS track } \\ \text { VHF } & =\text { Very High Frequency } \\ \text { W } & =\text { NATOTS track } \\ \text { X } & =\text { NATOTS track } \\ \text { Y } & =\text { NATOTS track } \\ Z & =\text { NATOTS track } \\ & \end{array}$

\section{Introduction}

$\mathrm{T}$ HE National Aeronautics and Space Administration (NASA) Langley Research Center (LaRC) has been developing a new airborne procedure, known as Automatic Dependent Surveillance-Broadcast (ADS-B) InTrail Procedure (ITP), to take advantage of the implementation of ADS-B. The United States, Australia and Europe have established programs to develop and implement ADS-B to improve Air Traffic Management. ${ }^{1-3}$ Benefits of ADS-B include increased surveillance range and a more extensive message set compared to existing technology. The ITP is intended to be used in non-radar (Radio Detection and Ranging) airspace that is employing procedural separation. Through the use of airborne ADS-B data, onboard tools, and a new separation standard based on these data and tools, aircraft will be able to make a new type of altitude change request to enable altitude changes that would not previously have been approvable. In support of the development of this procedure several experiments have been completed including human-in-the-loop studies evaluating both pilot and controller aspects of the ITP, safety analyses, and computerized batch processing studies investigating the operational impacts of the use of the ITP. This paper will present results of the computerized batch processing study and discuss some of the operational benefits that can be gained through the use of the ITP.

\section{Background}

The ITP is designed for use in non-radar procedural airspace. For this experiment, the North Atlantic Organized Track System (NATOTS) was selected. On a typical day, there are approximately 800-1,000 aircraft that cross the North Atlantic, where about half to two-thirds (400-600) of the traffic operate on the NATOTS. The other flights operate on non-structured routes, known as random routes that are uniquely designed and requested routes. In addition to the large number of aircraft, for an oceanic environment, the majority of the aircraft travel across the ocean during a relatively small window of time. This is done for scheduling reasons by the airlines to accommodate destination airport curfew restrictions as well as accommodating the most popular travel times of customers. Due to these policies, many of the flights operate on similar routes around the same time which in turn results in local congestion. Since most of the traffic is made up of similar aircraft types, there is a large demand for similar crossing 
altitudes. This generally requires that some aircraft fly at altitudes other than what they requested, which may not be as fuel efficient. The effect of this problem is also increased by the separation standards being used. In the North Atlantic, the separation standard currently being used is a 10 minute Mach Number Technique. Additional information on this technique can be found in the Application of Separation Minima for the North Atlantic Region. ${ }^{4}$

While there are occasional aircraft that climb or descend to more optimum altitudes during the oceanic crossing, most aircraft do not make any altitude change requests for the duration of the crossing. There are spaces at desirable altitudes on the track system into which an aircraft could climb or descend, but in today's system the pilots do not know where these openings are and therefore when to initiate a new request. One factor that contributes to this problem is that there is limited local surveillance available to pilots today. The result of this is that only about $6 \%$ (B. McPike [NATS UK] personal communication, October 28, 2004), of aircraft perform any altitude changes in current day operations, although this number does seem to be increasing. The range of ADS-B allows for improved surveillance of surrounding traffic and is greater than the current separation standards employed in the NATOTS. ADS-B IN can be used to provide a means of finding potential climb or descent opportunities that exist within the current system. This first benefit results from increased situation awareness (SA) of surrounding traffic that is achieved through a graphical cockpit display of traffic information (CDTI). A CDTI is not required for ITP, but it is expected that a CDTI would provide additional benefit to an ITP installation. While an increase in SA is of benefit, the ITP establishes new procedures and a proposed new separation standard to enable altitude changes that would not be possible under current operations. The ITP has been designed to take advantage of ADS-B technology that can enable inter-aircraft transmission and reception of position and other relevant aircraft information. ${ }^{5,6}$ The details of the ITP are explained in the next section.

\section{In-Trail Procedure}

The ITP is being developed by the RTCA/EUROCAE sponsored Requirements Focus Group (RFG) and the International Civil Aviation Organization (ICAO) Separation and Airspace Safety Panel (SASP). A complete description of the procedure can be found in the Safety, Performance and Interoperability Requirements (SPR) Document for the ATSA-ITP application (ED-159) document. ${ }^{7}$ The ITP is intended to enable altitude changes that would currently be blocked due to aircraft spaced at less than current separation standards at altitude(s) between the current and desired altitudes of a requesting aircraft. Standard separation is required between all aircraft at the current and the desired altitudes. This is possible through the use of ADS-B, onboard tools, and the new ITP. The following definitions are useful to help understand the ITP:

- The ITP Aircraft is the aircraft making an ITP request for an altitude change and has the necessary onboard tools, equipment and crew training.

- Reference Aircraft are one or two same direction aircraft at an intermediate altitude, that are transmitting qualified ADS-B data, and that meet the ITP initiation criteria.

- Same Direction occurs when the aircraft tracks or portions of the tracks fall within $+/-45$ degrees of each other.

- Same Track is a further restriction of Same Direction that occurs when the protected zones for each track overlap

- Intermediate altitudes include all altitudes between the ITP aircraft's current altitude and its requested altitude.

- The ITP initiation criteria include that reference aircraft must meet one of two conditions: if the ITP distance to a reference aircraft is equal to or more than 15 nautical miles (nmi) then the groundspeed difference must be less than or equal to 20 knots (kts) between the two aircraft or if the ITP distance to a reference aircraft is equal to or more than $20 \mathrm{nmi}$ then the groundspeed difference must be less than or equal to $30 \mathrm{kts}$ between the two aircraft.

- The ITP distance is defined as the distance between a Reference Aircraft and the ITP Aircraft; it is calculated as the difference in distance to a common point along each aircraft's track. There is no requirement that the common point be co-located with any form of navigational waypoint. This is shown graphically in Figure 1. 

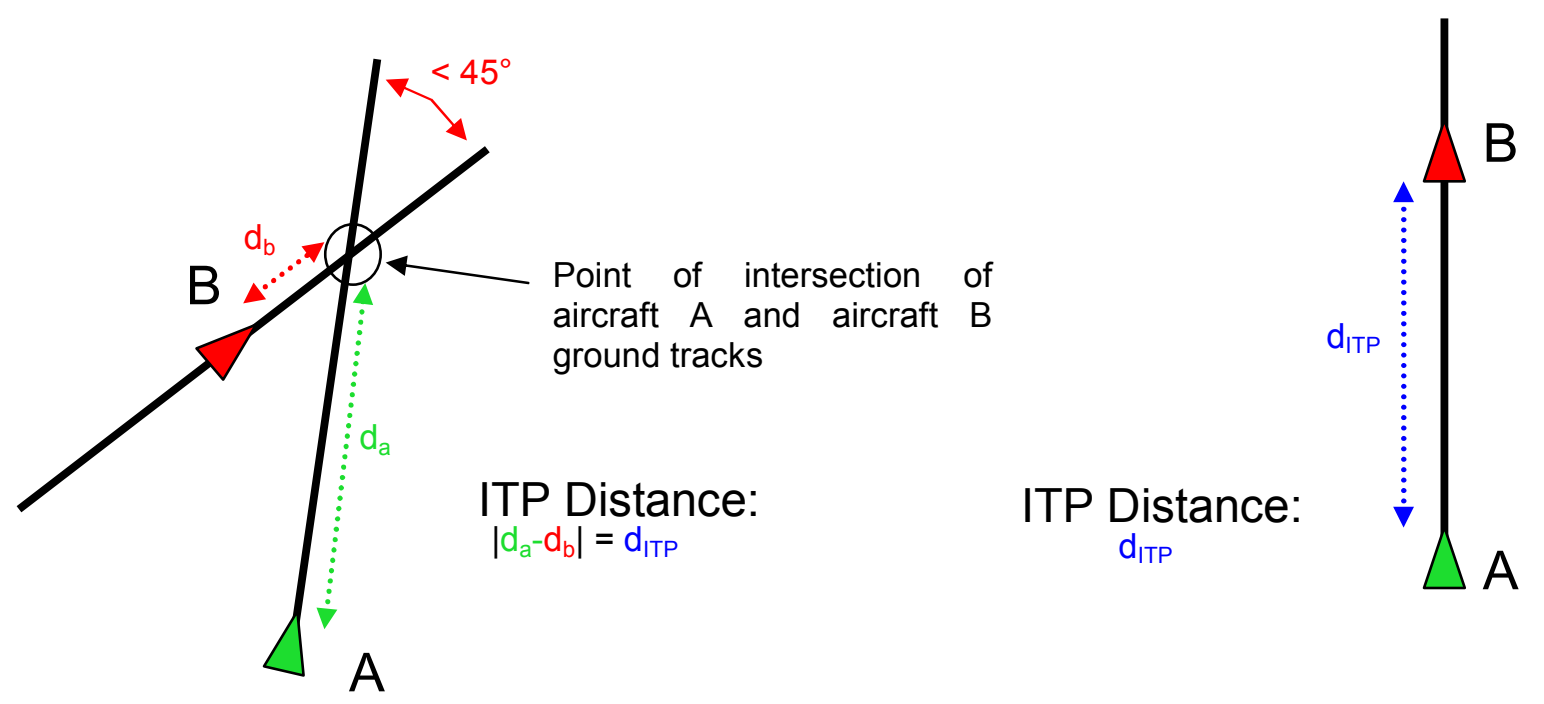

Figure 1. Calculation of ITP distance

The ITP aircraft, using on-board tools, makes use of ADS-B reports from nearby aircraft and determines which of the aircraft have qualified ADS-B data and meet the ITP criteria. The ADS-B reports must meet specific limits for the accuracy and integrity of the data in order to be used for the ITP. In order for the ITP to be requested, both the ITP aircraft and any reference aircraft must be same direction, and the initiation criteria must be met between the ITP aircraft and any reference aircraft. If these conditions are met, then the flight crew can make an ITP request to Air Traffic Control (ATC). An air traffic controller must review the request using all available information to ensure separation will exist with all aircraft not involved in the ITP, as well as ensure that ITP requirements are met. In order for a controller to approve an ITP, the following conditions must exist:

- the ITP aircraft can not be a reference aircraft for another ITP clearance;

- the ITP aircraft and each reference aircraft must be classified as Same Track;

- reference aircraft can not be in the process of maneuvering or be expected to maneuver; and

- the ITP and reference aircraft Mach numbers must be within 0.04 of each other if one aircraft is closing on another.

Upon receiving an ITP clearance from ATC, a flight crew must confirm that the initiation criteria are still met with each reference aircraft identified in the clearance prior to accepting the clearance and initiating the altitude change. Once the altitude change is completed, the ITP aircraft must report level at the cleared altitude.

The ITP can be applied equally during climb or descent maneuvers. Provided that all of the ITP criteria are met, any of the following aircraft configurations can be used:

1. The ITP aircraft is following one or two reference aircraft

2. The ITP aircraft is leading one or two reference aircraft

3. The ITP aircraft is leading one reference aircraft and following one reference aircraft

For configurations 1 and 2, if two reference aircraft are being used, then the aircraft must be located on separate intermediate altitudes. For configuration 3, the two reference aircraft can be located on the same or separate intermediate altitudes.

\section{Experiment Tool}

A desktop air traffic simulation computer program called Traffic Manager (TMX) was used to simulate the environment for this experiment. The simulation environment created for this experiment included the oceanic airspace, the NATOTS, multiple ATC centers, and the individual aircraft. TMX is a medium fidelity desktop simulation application designed for interaction studies of aircraft in present or future Air Traffic Management (ATM) environments. TMX was originally developed by the National Aerospace Laboratory (NLR) in The Netherlands, and it can serve as a stand-alone traffic simulator, scenario generator, scenario editor, experiment control station, data-recording tool, and rapid prototyping environment. Both the NLR and the NASA LaRC have continued to enhance and improve TMX, making it a valuable asset to many ATM research projects. ${ }^{8}$ 
TMX is capable of simulating up to 2,000 aircraft simultaneously with each aircraft using a six-degrees-offreedom dynamics model, augmented with performance parameters from the EUROCONTROL Base of Aircraft Data (BADA) database. ${ }^{9}$ Other features include:

- Gate to Gate Operations: includes approach and taxi

- Auto flight Model: basic altitude, heading, and speed modes, plus Flight Management System (FMS) modes with auto throttles and Required Time of Arrival functionality

- ADS-B Model: includes range limits

- Airborne Separation Assistance Systems (ASAS): conflict detection, resolution, and prevention systems selectable among multiple variants

- Airborne Precision Spacing: for merging and spacing operations

- Pilot Model: includes parameters for reaction time and scheduling of tasks

- Wind Model: 3D "truth" and predicted wind fields

- Weather Model: includes moving weather cells

- Data logging: time and event based

TMX also supports external connection interfaces to connect to full motion simulators and to integrate with the NASA LaRC Air Traffic Operations Laboratory (ATOL). Depending on the research need, TMX can operate either in real time or fast time mode. TMX can be modified to accommodate new and changing research requirements.

\section{A. Development}

In addition to the current functionality that exists in TMX, several enhancements were required for this research effort. The first enhancement that was necessary was the creation of the oceanic flight environment that exists in the North Atlantic. This included the addition of Oceanic Control Areas (OCAs), the ability to load in National Oceanic and Atmospheric Administration (NOAA) Global Forecast System (GFS) wind forecasts, ${ }^{10}$ and the ability to assign the NATOTS notice to airmen (NOTAM) messages as routes to aircraft. The second two processes also required the creation of an external program to convert the data into the correct format to be read into TMX. Since in the North Atlantic aircraft can use Controller Pilot Data Link Communication (CPDLC), it was necessary to expand and improve the existing CPDLC functionality within TMX. Among these enhancements was the addition of messages for position reports and ITP required messages. The next enhancement made was to the fuel model, and how the fuel flow calculation is performed. The core of the TMX performance model is based on the BADA database. In order to achieve the desired level of accuracy in the fuel flow model for this experiment, a new calculation method was implemented that uses a $4^{\text {th }}$ order polynomial function that is a curve fit to the data contained in Cruise-Mach tables. This improved model is only applied during the cruise portion of any flight. Due to proprietary restrictions on obtaining appropriate fuel flow data required to implement this improved fuel model, there are many aircraft types in TMX that still use the BADA calculations. The improved fuel model was implemented for ten aircraft types typically flown in the North Atlantic region and these were the only aircraft types used in this experiment.

The next major task required for this research was to redesign the pilot model within TMX. The existing model within TMX was not capable of performing all of the required tasks related to the ITP and oceanic airspace. By redesigning the entire model, the capability and realism of the pilot model has been significantly improved. The new pilot model handles tasks that in real-life could be manually completed (altitude requests) and automatically completed (position reports). The model is also now easily extendable to include functionality for new tasks, when they are needed. The creation and sending of position reports by each aircraft is one example of a new task that was added specifically for this research effort.

The last development effort was the creation of an ATC model within TMX. This was required in order to be able to simulate aircraft operating in the oceanic environment, to look into the effects of differences in the surveillance information available to pilots and controllers, and to examine the communications involved with each altitude change request. The ATC model was designed using the same architectural layout as the pilot model in order to make it expandable and multifunctional. The ATC model is based on OCAs, an ATC center is created for each sector loaded in the simulation. Aircraft flying within each OCA will send all communications to that ATC center. There is also coordination performed when an aircraft is near the boundary of sectors in that position reports will also be sent to the adjacent sector(s). There is not currently any coordination between adjacent ATC centers when a maneuver is requested near a boundary. 


\section{Experiment Design}

In this experiment there were four variables considered: 1) the ADS-B environment which was made up of the percent of aircraft in the scenario that were equipped with ADS-B OUT and the percent of aircraft in the scenario that were equipped with ADS-B IN, 2) the density of aircraft in the NATOTS, 3) if the aircraft equipped with ADSB IN were capable of performing the ITP, and 4) the request method used for track entry. The levels of ADS-B OUT equipage used were $30 \%, 60 \%$, and $90 \%$ and for ADS-B IN were $10 \%, 45 \%$, and $80 \%$ of all aircraft in the scenario. These two variables together describe an equipage level that provides the surveillance environment for each experiment condition. It was assumed that any aircraft equipped with ADS-B IN would also be equipped with ADS-B OUT. Therefore, cases that would result in a higher ADS-B IN than ADS-B OUT equipage rate were not considered. This combination of ADS-B OUT and ADS-B IN values yielded 6 equipage levels. A seventh level was used as the baseline condition in which none of the aircraft were equipped with ADS-B IN or ADS-B OUT. There were four traffic densities used for the total number of aircraft and the target values were $0.5,1.0,1.5$, and 2.0 times current traffic levels. Throughout the experiment and this paper, these traffic levels are referred to as Low, Medium, High and Ultra, respectively. Table 1 shows a summary of the recorded traffic data from March 25, 2006January 23, 2007. The average number of aircraft for each traffic density is shown in Table 2 along with an approximate ratio to the average number of aircraft from the recorded traffic data. Due to the complexities of generating traffic flows with realistic characteristics, the traffic levels generated for this experiment resulted in slightly less than the nominal target values. These are the values shown in Table 2, and used in the remainder of this paper.

Table 1. Real day traffic density level

\begin{tabular}{|c|c|c|c|}
\hline $\begin{array}{l}\text { Minimum } \# \text { of } \\
\text { Aircraft }\end{array}$ & $\begin{array}{l}\text { Maximum } \\
\text { Aircraft }\end{array}$ & $\begin{array}{lll}\begin{array}{l}\text { Average } \\
\text { Aircraft }\end{array} & \# \quad \text { of } \\
\end{array}$ & $\begin{array}{l}\text { Standard } \\
\text { Deviation }\end{array}$ \\
\hline 61 & 301 & 232.15 & 30.59 \\
\hline
\end{tabular}

Table 2. Experiment traffic density levels

\begin{tabular}{|l|l|l|l|l|}
\hline & Low & Medium & High & Ultra \\
\hline $\begin{array}{l}\text { Ratio to Real } \\
\text { Traffic }\end{array}$ & 0.5 & 1.1 & 1.4 & 1.9 \\
\hline $\begin{array}{l}\text { Number of } \\
\text { aircraft }\end{array}$ & 125 & 261 & 318 & 456 \\
\hline
\end{tabular}

The fourth variable of ITP capability was varied as either $0 \%$ (SA only) or $100 \%$ (SA+ITP) of the ADS-B IN equipped aircraft. This parameter allowed the ADS-B IN equipped aircraft to either use only the SA aspects of an ADS-B/ITP display or to combine that information with the increased flexibility of the ITP when making altitude change requests. The use of ADS-B information for situation awareness allowed the pilot model to make more informed altitude change requests, even when not equipped with the ITP. The relationship of these three variables and the values used are represented in Table 3.

Table 3. Experiment design matrix

\begin{tabular}{|c|c|c|c|c|c|c|c|c|c|c|c|c|c|c|}
\hline & & \multicolumn{13}{|c|}{$\%$ ADS-B OUT \% ADS-B IN } \\
\hline \multirow{5}{*}{ 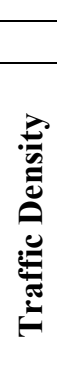 } & & $\begin{array}{lll}0 & 0\end{array}$ & \multicolumn{2}{|c|}{\begin{tabular}{l|l}
30 & 10
\end{tabular}} & \multicolumn{2}{|c|}{$\begin{array}{lll}60 & 10\end{array}$} & \multicolumn{2}{|c|}{$90 \_10$} & \multicolumn{2}{|c|}{$60 \_45$} & \multicolumn{2}{|c|}{9045} & \multicolumn{2}{|c|}{9080} \\
\hline & $\begin{array}{l}\text { Low } \\
(0.5 X)\end{array}$ & $\overline{\mathbf{S A}}$ & SA & $\begin{array}{l}\text { SA+ } \\
\text { ITP }\end{array}$ & SA & $\begin{array}{l}\text { SA+ } \\
\text { ITP }\end{array}$ & SA & $\begin{array}{l}\text { SA+ } \\
\text { ITP }\end{array}$ & SA & $\mathbf{S A}+$ & SA & $\begin{array}{l}\text { SA+ } \\
\text { ITP }\end{array}$ & SA & $\begin{array}{l}\text { SA+ } \\
\text { ITP }\end{array}$ \\
\hline & $\begin{array}{l}\text { Medium } \\
(\mathbf{1 . 1 X})\end{array}$ & SA & SA & $\begin{array}{l}\text { SA+ } \\
\text { ITP }\end{array}$ & SA & & SA & $\begin{array}{l}\text { SA+ } \\
\text { ITP }\end{array}$ & SA & & SA & $\begin{array}{l}\text { SA+ } \\
\text { ITP }\end{array}$ & SA & \\
\hline & $\begin{array}{l}\text { High } \\
(1.4 X)\end{array}$ & SA & SA & $\begin{array}{l}\text { SA+ } \\
\text { ITP }\end{array}$ & SA & $\begin{array}{l}\text { SA+ } \\
\text { ITP }\end{array}$ & SA & $\begin{array}{l}\text { SA+ } \\
\text { ITP }\end{array}$ & SA & $\begin{array}{l}\text { SA+ } \\
\text { ITP }\end{array}$ & SA & $\begin{array}{l}\text { SA+ } \\
\text { ITP }\end{array}$ & SA & $\begin{array}{l}\text { SA+ } \\
\text { ITP }\end{array}$ \\
\hline & $\begin{array}{l}\text { Ultra } \\
(1.9 X)\end{array}$ & SA & SA & $\begin{array}{l}\text { SA+ } \\
\text { ITP }\end{array}$ & $\mathbf{S}$ & $\begin{array}{l}\text { SA+ } \\
\text { ITP }\end{array}$ & $\mathbf{S}$ & $\begin{array}{l}\text { SA+ } \\
\text { ITP }\end{array}$ & SA & $\begin{array}{l}\text { SA+ } \\
\text { ITP }\end{array}$ & SA & $\begin{array}{l}\text { SA+ } \\
\text { ITP }\end{array}$ & SA & $\begin{array}{l}\text { SA+ } \\
\text { ITP }\end{array}$ \\
\hline
\end{tabular}


Table 3 represents only half of the experiment design matrix, which was repeated across the remaining experiment variable (request method). The variable of request method determined what altitude an aircraft would request when approaching the entrance of the NATOTS. All aircraft would look at what the optimum fuel flow altitude would be at a specified look-ahead time past the entrance of the track. The request method would either use that altitude (RM0) or would add one thousand feet to that altitude (RM1). These two request methods are based on request methods used by airlines in today's operations. Some airlines flight-plan with the expectation of making a climb during the flight and therefore request entry into the track structure at the current optimum altitude (RM0). Other airlines do not expect to climb at all and therefore determine a compromise altitude (between optimum at entry and optimum at exit) which usually occurs about 1,000 feet above the current optimum altitude at entry (RM1).

The portion of the experiment design matrix shown in Table 3 contains 52 cells. When this is duplicated, the result is a total of 104 cells for the entire experiment matrix. In order to provide a statistically significant number of samples throughout the experiment, each of the 104 cells had 18 replicates run in it. A statistical power analysis was performed to determine that 18 replicates was the minimum number that would be needed across all of the variables of interest. Each of the 18 replicates was an independent traffic flow into the NATOTS. Each traffic flow was representative of a single day at the specific traffic density and was randomly generated from a distribution function such that the desired NATOTS characteristics would be simulated (e.g. traffic distribution across the NATOTS, distribution of aircraft arrivals into the NATOTS, and total number of aircraft). When accounting for the 18 replicates per experiment cell, there were a total of 1,872 individual scenarios run through TMX for data collection in this experiment.

\section{Simulation Validation and Scenario Creation}

The ability of TMX to accurately simulate current day operations was of critical importance in this experiment. A significant portion of the development effort was spent making this possible and validating the simulation against data collected March 7-15, 2005 and March 26, 2006 through January 23, 2007. The primary comparisons were the distribution of aircraft between the active tracks, the distribution of aircraft in time for the whole NATOTS, and the total number of aircraft that passed through the NATOTS. The data collected from NavCanada's Traffic Density Analyzer (TDA) between March 26, 2006 and January 23, 2007 was used to determine the average distribution of aircraft between the active tracks of the NATOTS. This is an important aspect of the NATOTS operation since not all of the tracks are loaded with an equal number of aircraft. The NATOTS is designed, every 12 hours, to be either centered on the jet stream during eastbound operations or avoiding the jet stream during westbound operations. This results in most of the traffic requesting entry on the central tracks, leaving the outer tracks less populated for eastbound flights. An example of this distribution is shown in Figure 2 for the traffic load on March 7, 2005, along with the average across all 18 medium density traffic flows within the experiment. March 7, 2005 is the date that was used for the NATOTS and wind field throughout the experiment. Due to the Southern most track having a significantly lower count of aircraft, track Zulu (Z) was not included in this experiment. 


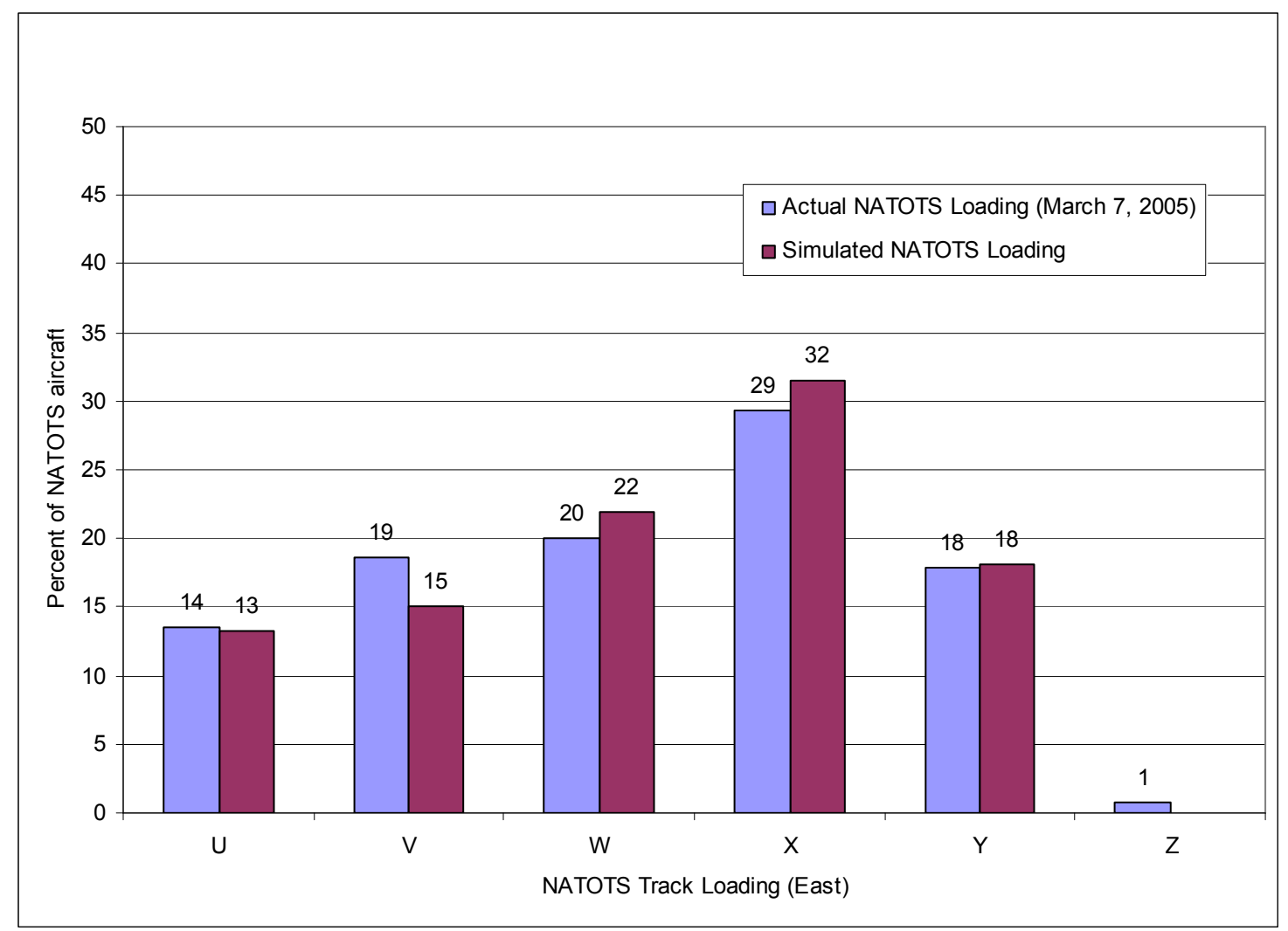

Figure 2. NATOTS loading comparison

For the comparison of the traffic distribution in time, recorded data from Shanwick Oceanic Control for the period of March 7-15, 2005 was used. The number of aircraft in the NATOTS was counted at 60 second intervals. This showed how the density of aircraft in the system changed with time. This distribution also is not uniform between the active tracks of the NATOTS. In order to be able to create scenarios that would contain a similar distribution to the real NATOTS traffic loads, a distribution function was created within TMX that could be adjusted through input parameters to achieve the desired density and distribution of aircraft. This function is based on the generation of an exponentially distributed random number and a nominal creation interval between aircraft; this is performed on a per track basis. The input parameters were calibrated to create traffic flows with a distribution similar to that of the March 2005 data. The calibration was performed independently for each track used in the experiment. The target traffic densities based on the data from the TDA were used to ensure that the traffic flows had similar levels of aircraft to what was desired. The comparison of both the distribution and the traffic density within the NATOTS was used as the basis of selecting which traffic flows would be used in the experiment. This process resulted in the required 18 traffic flows for each of the four traffic densities of the experiment. Figure 3 shows how the average distribution of the final experiment traffic flows compare to the average distribution of the March 2005 data. This graph covers the time period during which the eastbound tracks were active ( $\sim 12$ hours) and includes the count of all tracks combined. The actual data shown is the average of the nine days worth of data that was collected, and each experiment density is the average of the 18 flows that were simulated. Since the actual traffic distribution data only exists for one traffic density, the times used to create the higher traffic densities were multiplied by a scalar resulting in an estimate of how the curve would scale with increased traffic densities. 


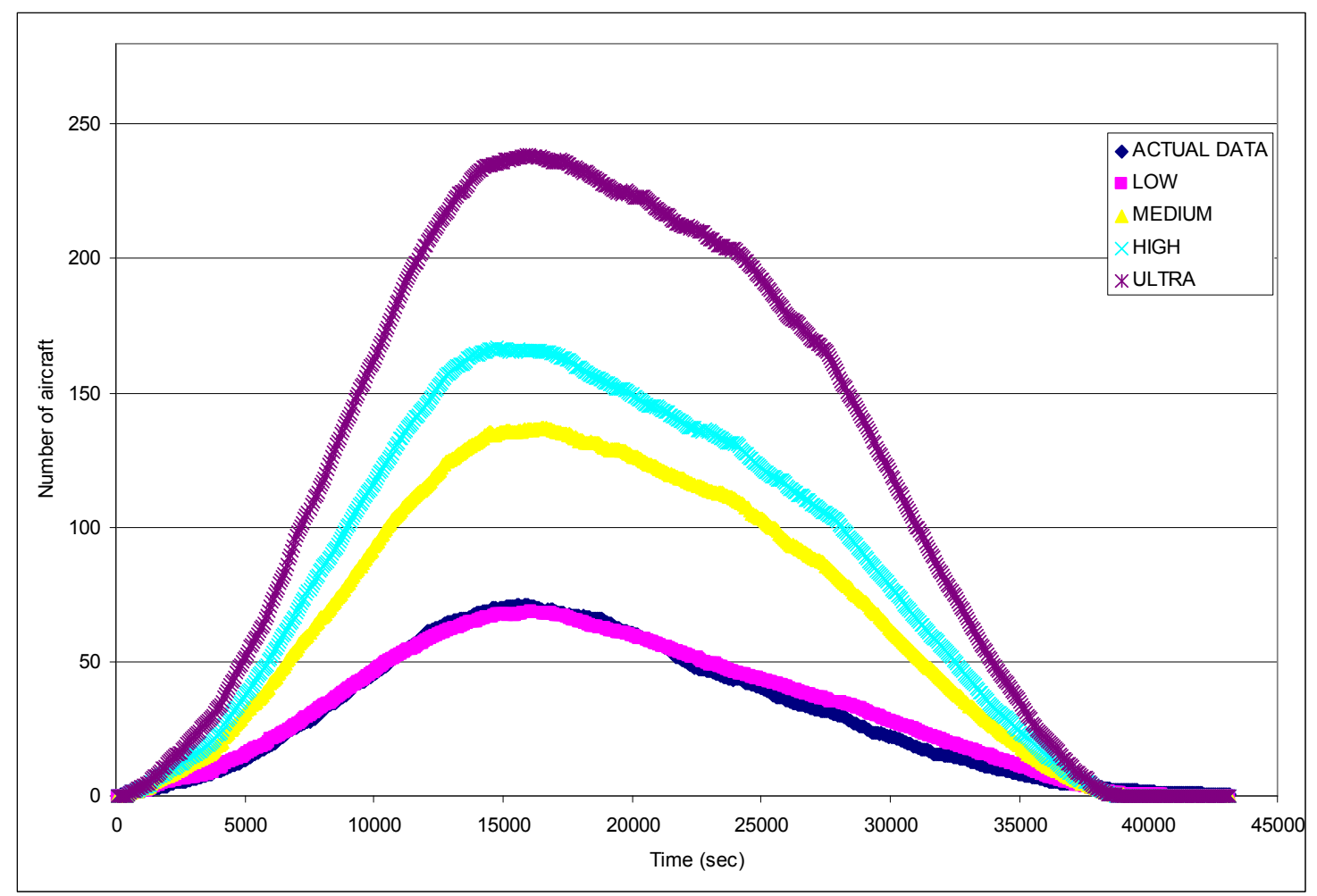

Figure 3. NATOTS traffic distribution in time

Once the 72 experiment traffic flows (18 flows $* 4$ densities) were selected, the aircraft had to be loaded onto each track at specific altitudes such that the required separation would exist throughout the duration of each flight. This track loading process made use of the ATC model to assign each aircraft a crossing altitude. The assigned altitude was based on the entry altitude request that each aircraft made to ATC prior to entering the NATOTS. The ATC model would attempt to load each aircraft at their requested altitude. If this was not possible, ATC would check for an altitude that would provide required separation in an expanding altitude envelope from the requested altitude. For this experiment, the sequence that ATC used for loading is shown in Table 4. This sequence was developed with support from team member observations of track loading operations made during tours of NATOTS control centers for Gander and Shanwick OCAs.

Table 4. ATC altitude assignment sequence

\begin{tabular}{|l|c|}
\hline Attempt & $\begin{array}{c}\text { Delta from } \\
\text { Requested Altitude } \\
\text { (feet) }\end{array}$ \\
\hline 1 & 0 \\
\hline 2 & +1000 \\
\hline 3 & +2000 \\
\hline 4 & -1000 \\
\hline 5 & -2000 \\
\hline 6 & -3000 \\
\hline 7 & +3000 \\
\hline 8 & -4000 \\
\hline 9 & +4000 \\
\hline 10 & +5000 \\
\hline
\end{tabular}


When an aircraft could not be loaded at any altitude in this sequence such that it would maintain the required separation, it was removed from the simulation. The removal of an aircraft was a rare occurrence, and did not significantly impact the average densities of the resulting experiment scenarios. Aircraft were not allowed to be assigned an altitude that was not within the defined NATOTS, or that was not within the flight envelope of the aircraft. The remaining aircraft were recorded into a new scenario. This loading process of the aircraft to a specific altitude created the baseline scenarios for the experiment, a total of 144 ( 72 traffic flows $* 2$ request methods).

The following figure shows how the density of each experiment traffic flow compares to the recorded TDA data for eastbound tracks. The number of flights that occur on the westbound tracks is usually comparable to the eastbound tracks, resulting in about 400-600 flights on the NATOTS each day. Westbound tracks were not simulated in this experiment due to previous results that showed no significant difference between eastbound and westbound flights. Figure 4 shows the 18 traffic flows per density when run with the RM0 request method. There were very few differences that occurred when aircraft were loaded into the system using the RM1 request method. It may be noticed that the actual data in this graph is aligned closest with the medium density data, and in the previous figure the actual data aligned best with the low density data. The primary reason for this difference is the dates for which the data was collected. In March 2005 the traffic levels in the North Atlantic were not as high as they were during the March 2006-January 2007 time period. Table 5 shows the average number of flights across the two actual data sets and the four experiment densities. It can be seen that the March 2005 data is consistently aligned with the low density for both distribution (Figure 3) and total number of flights (Table 5).

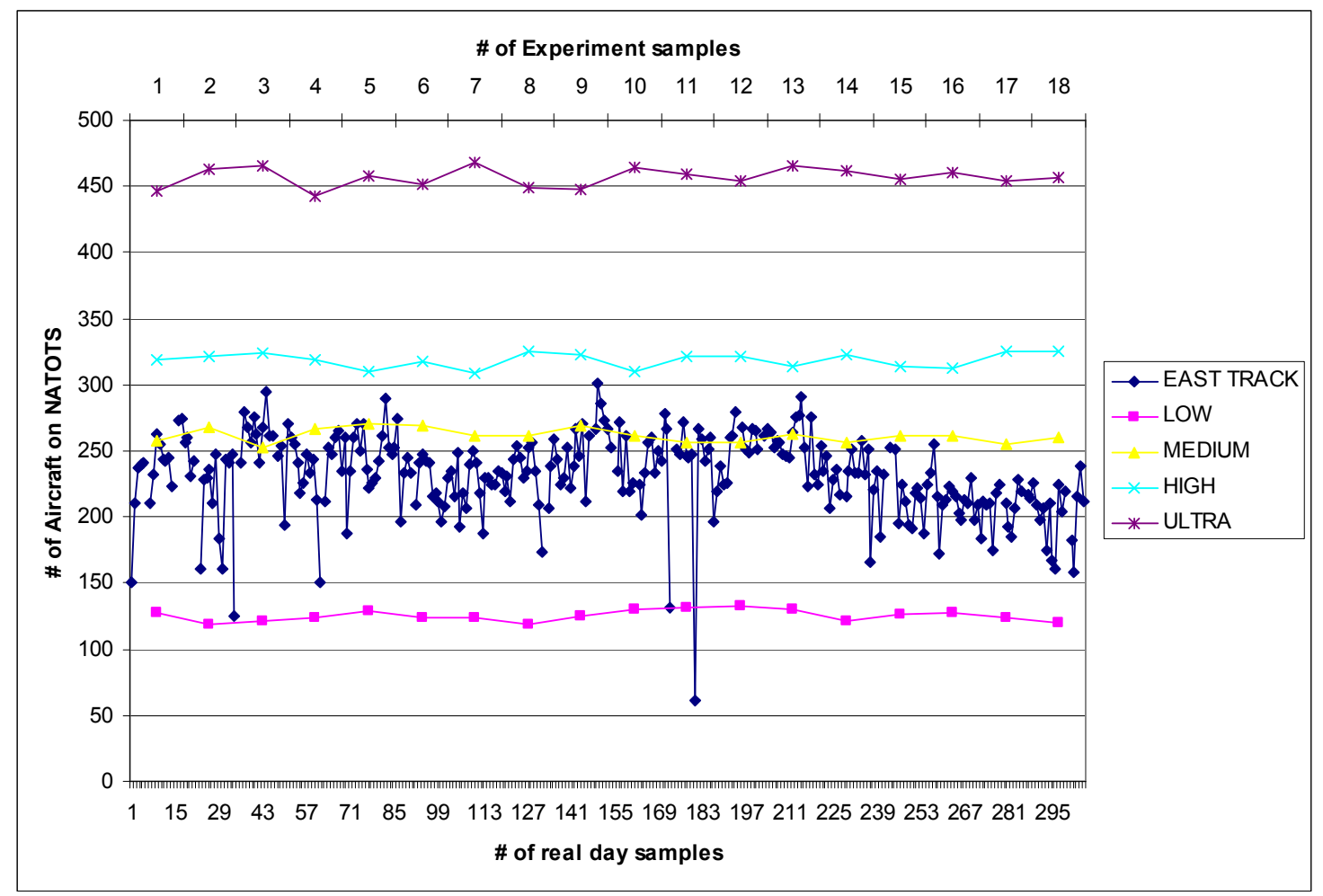

Figure 4. Density comparison for requested entry at optimum altitude (RM0)

Table 5. Average number of flights in the NATOTS

\begin{tabular}{|l|l|l|l|l|l|l|}
\hline & \multicolumn{4}{|l|}{ Actual Data Sets } & \multicolumn{4}{l|}{ Experiment Data Sets } \\
\hline & $\begin{array}{l}\text { March } \\
2005\end{array}$ & $\begin{array}{l}\text { March 2006- } \\
\text { January 2007 }\end{array}$ & Low & Medium & High & Ultra \\
\hline Average & $\mathbf{1 2 8 . 6}$ & 232.2 & 125.3 & 261.5 & 318.6 & 456.7 \\
\hline
\end{tabular}


The process of requesting an entry altitude and ATC assigning a crossing altitude was only performed during the creation of the baseline scenarios. After the baseline scenarios were created, they were used to create the remaining experiment scenarios by only adjusting what equipment each aircraft was created with. This process did not involve the use of TMX, but a stand alone application. This application would use a baseline scenario and a series of random number sequences. For each baseline scenario there were six groups containing two sequences of random numbers. Each group corresponded to an equipage level in the experiment matrix (30_10,60_10,60_45, 90_10, 90_45, or 90_80). One sequence per group contained the numbers for the aircraft that would be equipped with only ADS-B OUT, and the other contained the numbers for the aircraft that would be equipped with both ADS-B OUT and ADS-B IN. These numbers referred to the sequence in which the aircraft were created in the scenario. When the sequences were generated they were kept self consistent across equipage levels. For example, once an aircraft was equipped with ADS-B OUT, (e.g., at the $30 \%$ level) it would at least be equipped with ADS-B OUT in any higher equipage environments (i.e., $60 \%$ or $90 \%$ levels). The same was true for the creation of the ADS-B IN equipage sequences. This process only changed which aircraft were equipped with ADS-B, but not their position or flight plan in the scenario.

Each ADS-B equipage environment (6 levels) and procedural capability (SA or SA+ITP) generated a new experiment scenario resulting in a total of 12 experiment scenarios, in addition to the original baseline scenario. This was repeated for each of the 144 baseline scenarios, yielding all 1,872 scenarios used in the experiment [144 baseline $+(12 * 144)$ experiment scenarios]. These scenarios were then run through TMX to perform the data collection for the experiment.

\section{Assumptions and Configurations}

In addition to the creation of the experiment scenarios, there were some assumptions and configuration settings needed for the simulation to operate as a realistic environment. A key assumption was the frequency and time at which aircraft would make an altitude change request. None of the aircraft were allowed to make any altitude change requests for the first 10 minutes they were in the track system. This was to ensure that aircraft would not be approved for a maneuver that would place them into conflict with an aircraft that had not been created yet. This is based on current operations, because if an aircraft could change altitude within the first 10 minutes (current required separation), then ATC would have allowed the aircraft to enter at that altitude. All aircraft were also restricted from making requests for the last $100 \mathrm{nmi}$ of the track system. This was done for two reasons, the first being that once an aircraft and the trailing aircraft enter radar coverage near the exit of the track system, the required separation is reduced to $5 \mathrm{nmi}$ instead of 10 minutes. Very High Frequency (VHF) radio coverage is also available at that point, making any altitude change requests much easier and faster to communicate. The second reason to restrict the requests near the exit was to avoid any conflicts during data analysis. Since the aircraft were deleted from the simulation at the track exit, the trailing aircraft could (without this restriction) be cleared for a maneuver that would not be approvable had the first aircraft still been in the simulation. As a result of all these restrictions, aircraft were only allowed to make altitude change requests during the period 10 minutes after entering the tracks to $100 \mathrm{nmi}$ before exiting the tracks.

The frequency at which aircraft could make requests was set differently depending on if the aircraft was equipped with ADS-B IN or not. For the non-ADS-B IN equipped aircraft (comparable to the vast majority of today's aircraft) they could make a single altitude change request when approaching the sector transition between Gander and Shanwick, if it was desired to move closer to the optimum fuel burn altitude. This point occurs near the half-way point through the NATOTS crossing. This is similar to how operations are conducted currently in the NATOTS. In order to maintain a realistic number of altitude changes actually being performed in relationship to current day operations, not all of the requests made that could be approved were approved. Of the valid requests made by non-ADS-B IN equipped aircraft, the requests that were approved were intended to result in about $6 \%$ of the aircraft being able to maneuver. The selection of which valid requests were approved was done on a random basis. The result was that the actual number of requests approved for non-ADS-B IN equipped aircraft was between $2 \%$ and $8 \%$ of the aircraft, depending on the particular scenario. This restriction was not applied to aircraft equipped with ADS-B IN, where all approvable requests were approved. The ADS-B IN equipped aircraft were allowed to make an altitude change request at any point during the crossing provided they had not done so in the prior 10 minutes. The last assumption related to when aircraft could make altitude change requests has to do with making a follow-up request. Follow-up requests were allowed when an aircraft had a request denied. This method would try to get closer to the originally desired altitude, and would be repeated for each altitude that appeared available from the cockpit. This process stopped when there were no more altitudes between the present and near-optimum altitudes, or when a request was approved. 
Another critical assumption was the method that the pilot model used to determine what type of altitude change was appropriate based on available traffic information. There were three possible outcomes that could result from consideration of an altitude change request: no altitude change request, a standard (non-ITP) altitude change request, or an ITP altitude change request. The type of request and amount of available information depended on the equipment each aircraft had. The first step of the process was to determine if a flight level change was desired to fly closer to the optimum altitude. It was assumed that an aircraft would always climb if the optimum fuel flow altitude was higher than the current altitude. It was also assumed that an aircraft would only descend towards the optimum fuel altitude if the difference was greater than 1,000 feet. If an aircraft was assigned a higher altitude than the pilot model requested, then it was permitted to descend at most to the original requested entry/crossing altitude.

Once it was determined that an aircraft wanted to change altitude, there were two primary means of traffic information to check prior to making a request: Traffic alert and Collision Avoidance System (TCAS) and ADS-B. All aircraft in the experiment were equipped with a TCAS. Since the effective range of TCAS is approximately 30 $40 \mathrm{nmi}^{11}$ (though some new TCAS do have a greater range of 80-100 nmi), surveillance of surrounding traffic on the TCAS display was limited. To simulate this result in the experiment, TCAS only equipped aircraft were not considered "visible" to the pilot model when they were further than $40 \mathrm{nmi}$ away. The second means of surveillance of surrounding traffic that was available to some of the aircraft was the use of ADS-B IN information. The effective range of ADS-B used in this experiment was 190-200 nmi. Due to the criteria of the ITP, Table 6 was designed to control what requests the pilot model would make.

Table 6. TMX pilot model request availability

\begin{tabular}{|l|l|l|}
\hline Traffic Aircraft Range & Traffic at Desired Altitude & Traffic at Intermediate Altitude \\
\hline$<15 \mathrm{nmi}$ & None & None \\
\hline$>=15 \mathrm{nmi} \&<60 \mathrm{nmi}$ & None & ITP \\
\hline$>=60 \mathrm{nmi} \&<160 \mathrm{nmi}$ & Standard & ITP \\
\hline$>=160 \mathrm{nmi}$ & Standard & Standard \\
\hline
\end{tabular}

The information contained in Table 6 was used to evaluate the available request based on each visible traffic aircraft, and the most restrictive request would be made after all visible aircraft were evaluated. The most restrictive condition was when no request could be made followed by an ITP request and a standard (non-ITP) request. The range differentiation points were selected as follows:

- $15 \mathrm{nmi}$ is the minimum initiation distance for an ITP request. If there was a "visible" traffic aircraft within $15 \mathrm{nmi}$ there were no valid requests that could be made.

- $60 \mathrm{nmi}$ was selected because it is slightly less than the nominal separation being used. It is less to increase the likelihood of valid requests being made during cases when separation of aircraft might be near the limits of allowable separation.

- $160 \mathrm{nmi}$ comes from the separation standards used in the North Atlantic, and is a practical limit of what could be considered a maximum range required for current separation standards.

In real operations, ATC can always approve a less restrictive procedure than what is requested. For example if an aircraft requests an ITP, ATC could approve a standard climb if required separation exists, but an ITP could not be approved if a standard request was made. The other reason for this approach is that even in real day operations the pilots do not usually know the exact separation standard being applied to their aircraft; this approach to requests captures the idea that if an altitude change might be possible, pilots should make a request and try to take advantage of the opportunity.

\section{Results and Discussion}

Due to the extensive nature of this experiment, only a portion of the results obtained is included here. For complete results see Ref. 12. The two primary aspects of the results that are included in this paper examine the benefits in terms of request approvals and fuel burn. Within the results section, the traffic densities will be referred to as Low, Medium, High, and Ultra, corresponding to the multipliers of 0.5, 1.1, 1.4, and 1.9 described earlier.

\section{A. Request Approvals}

Figure 5 and Figure 6 are plots of the percent of flight level change requests that were approved versus the ADSB equipage levels for 8 different experiment conditions. The 8 variations shown are traffic density levels and 
whether the flight level change was approved based on SA alone or SA + ITP. The values plotted are an average across the 18 traffic flows tested for each combination of experiment parameters. As the number of ADS-B IN equipped aircraft increased, the percent of altitude change requests approved also increased. This is expected because aircraft equipped with ADS-B IN are assumed to also be equipped with ADS-B OUT, which results in more potential reference or target aircraft. However, the percent of the altitude change requests that were approved decreased as the density of traffic increased. This is shown in Figure 5 for the RM1 request method and Figure 6 for the RM0 request method. These figures show a direct relationship between the percent of aircraft equipped with ADS-B IN and the percent of requests approved. Figure 6 shows that the approval rates are slightly higher with the RM0 entry requests than with the RM1 entry requests shown in Figure 5. For example under the conditions of only using SA at the medium traffic density, around $61 \%$ of the requests were approved using the RM1 request method, compared to around $70 \%$ using the RM0 request method under the same conditions. There is only a slight difference between the curves for SA versus SA+ITP for any combination of conditions. The main cause of this is that the majority of the altitude change requests made were non-ITP requests, even when aircraft were capable of using the ITP. This also is the reason that there is fluctuation between whether SA or SA+ITP has a higher approval rate for specific conditions.

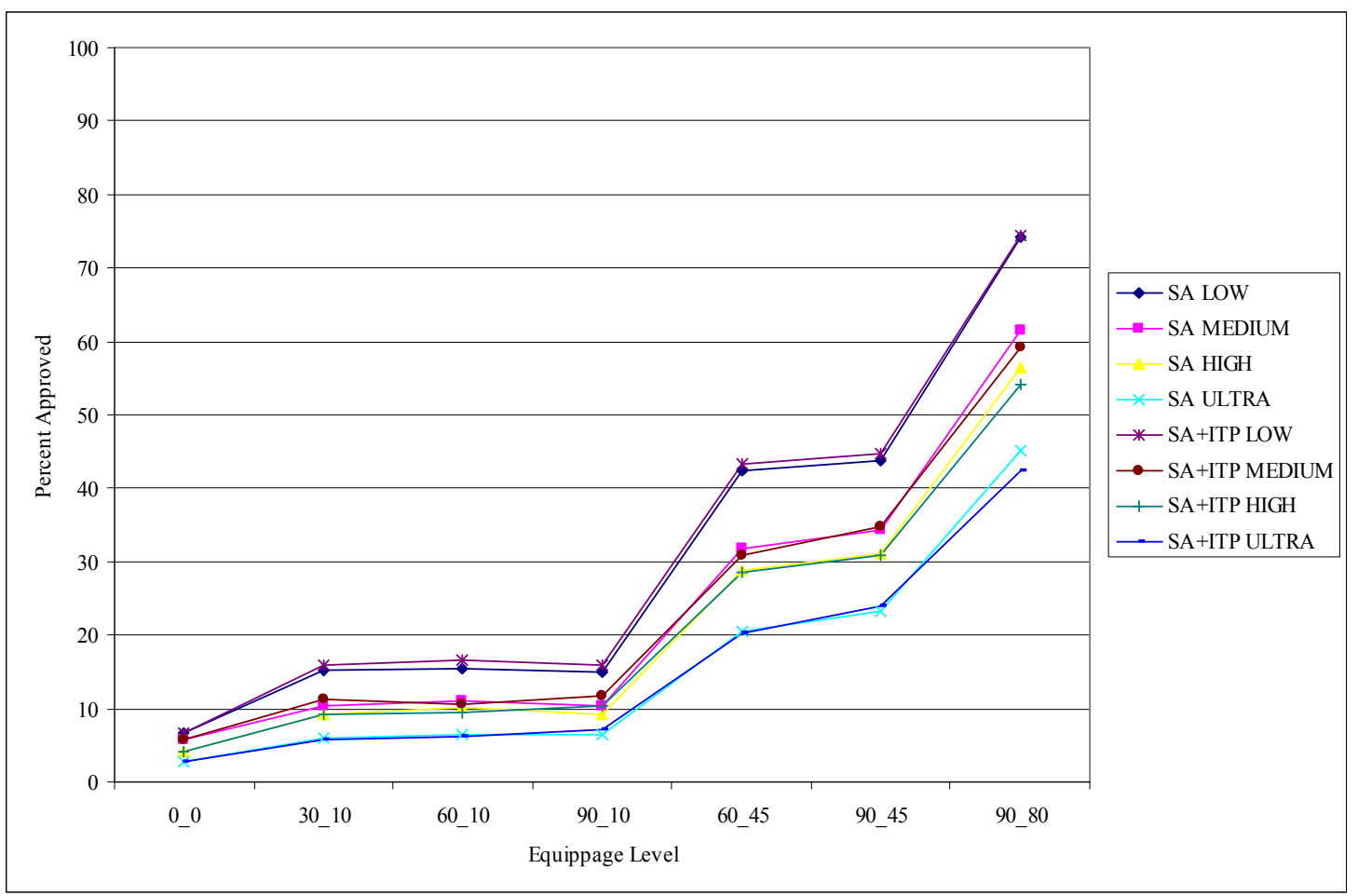

Figure 5. Approval rate of altitude change requests; Requested compromise entry altitude (RM1) 


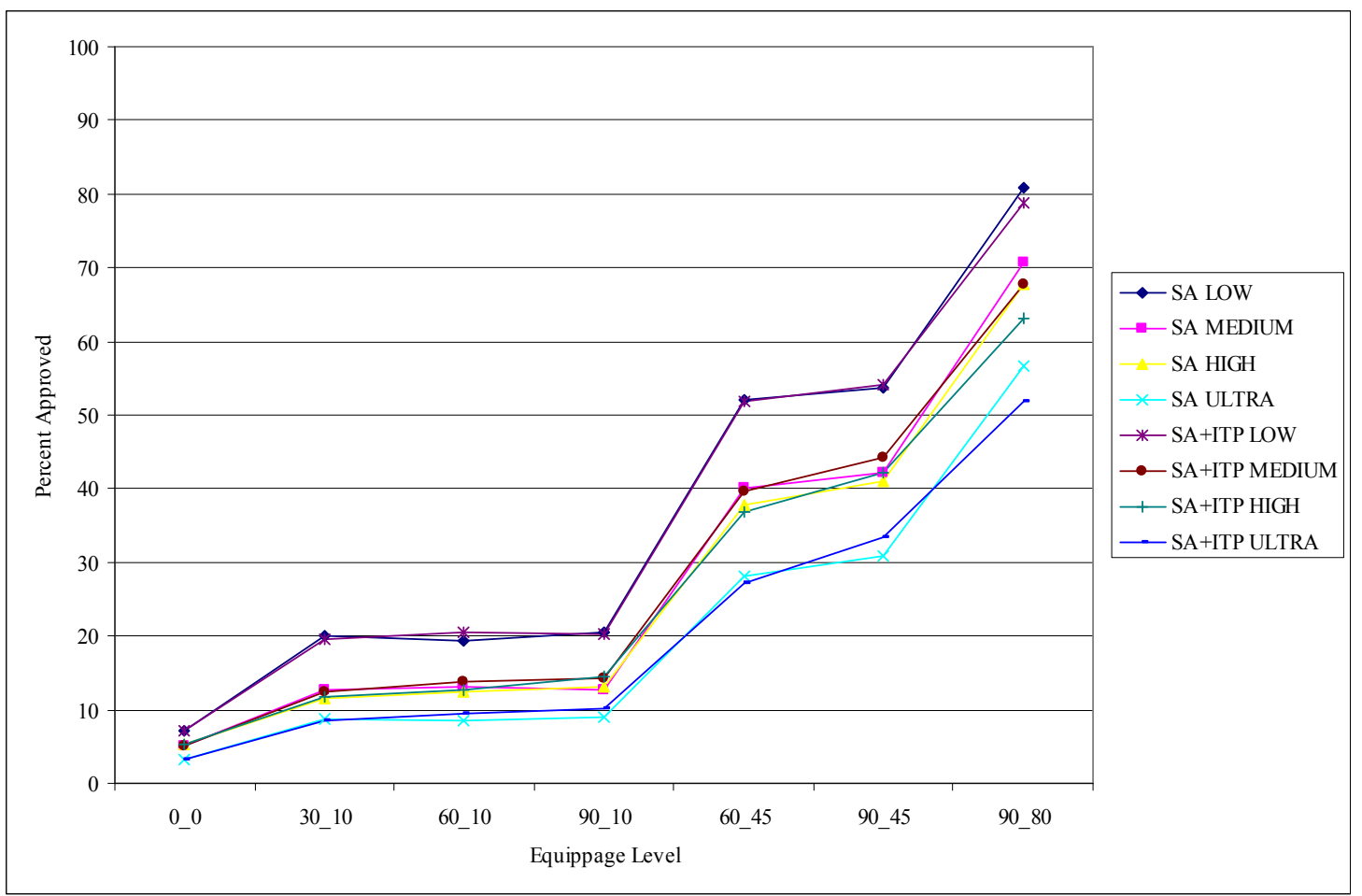

Figure 6. Approval rate of altitude change requests; Requested optimum entry altitude (RM0)

While the data shows an increase in request approvals when using SA and ITP, it should be emphasized that these opportunities to climb or descend are not created by either SA or the ITP capability tested in this experiment. Openings for aircraft to climb or descend exist in the track structure today, but aircraft are not aware of when it is possible to make use of these openings. An ADS-B IN display can provide a way to identify and make use of these opportunities. Figure 7 shows the percent of altitude change requests that could have been approved under the baseline conditions (current operations) using the request restrictions discussed earlier. Under traffic levels comparable to today (medium density) if all of the aircraft that wanted to change altitude made a request, than about half of the requests could have been approved. The reason for the RM1 method having fewer opportunities is that the aircraft are nominally starting 1,000 feet above their optimum, so there is a longer period of time before any change would be efficient. The decreasing opportunities with increasing traffic density occur because the "holes" on the track that an aircraft could climb or descend into are now being filled from the start of the track with additional aircraft. While similar opportunities exist in today's system, if all aircraft were to start asking every time an altitude change was desired, the Air Traffic Service Provider (ATSP) could become overwhelmed. The most effective approach to take advantage of the opportunities that exist for improving flight efficiency through altitude changes is to provide a means by which the aircraft can make more informed requests. Introduction of ADS-B technology and the ITP can provide information to improve when pilots make requests and give them increased flexibility when trying to change altitudes. 


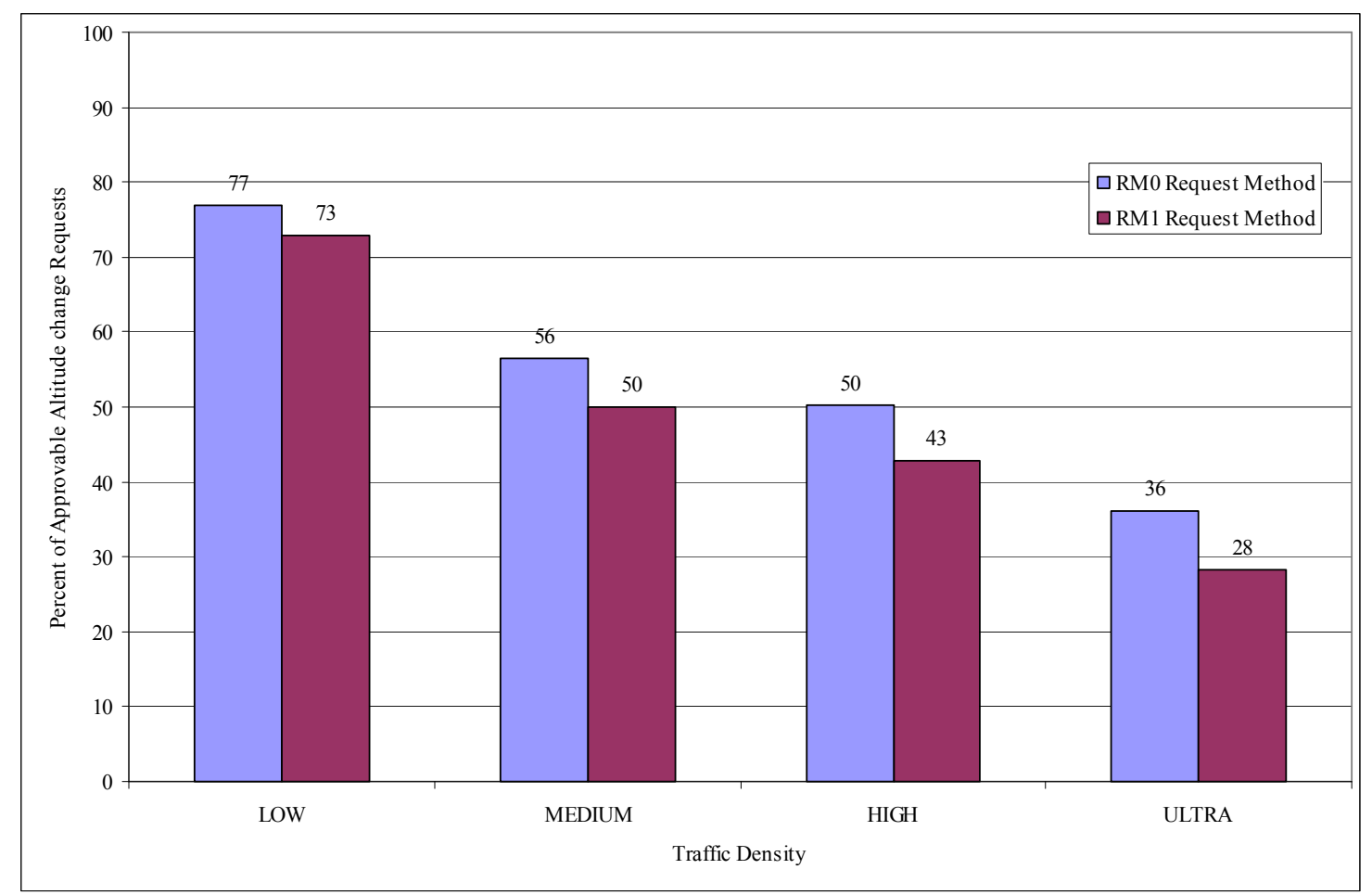

Figure 7. Available maneuvers in baseline scenarios

\section{B. Fuel Burn}

The primary variable used for comparisons in the analysis of the data from this experiment was the total fuel burn for a given flight normalized by the flight time for that flight. This normalization is required because the duration of flight was not always constant between the baseline and experiment scenarios. The differences were primarily caused by different wind fields and different fuel flow rates as a result of altitude changes. The fuel savings for a given flight is calculated as the difference in the normalized fuel burn in the baseline (no ADS-B equipage level) and the equipage level being investigated. This variable can be compared across equipage levels for each individual aircraft to create distributions of how many aircraft experienced a benefit or averaged together for a system-wide comparison.

Figure 8 and Figure 9 show the system-wide averages in fuel savings for the RM1 and RM0 entry request methods, respectively. Both cases show a general trend that there is an inverse relationship between aircraft density and the average fuel savings of aircraft. This can be shown since with each increase in traffic density, low up to ultra, a decrease in the average fuel savings occurs when comparing the same experiment conditions. The combination of SA+ITP under the same experiment conditions was shown to be more efficient than the use of SA alone. The contribution in fuel savings attributed to SA is greater than, or equal to, the contribution provided by the ITP in the SA+ITP conditions. This difference is greater with lower traffic densities, as shown by the proximity of the two low density curves and larger separation between the two ultra density curves in Figure 9. This is caused by the fact that as the traffic density increases the use of ITP to make altitude changes is needed more frequently. It should be noted that the savings in the RM0 entry case are again higher than in the RM1 entry case. In general there is a larger system benefit from an increase in ADS-B IN than from an increase in ADS-B OUT equipage. This can be seen by comparing the results for the three ADS-B IN cases of $10 \%$, to the three ADS-B OUT cases of $90 \%$. This is most likely a result of the increased number of aircraft gaining benefit from having ADS-B equipage. In both Figure 8 and Figure 9 the increase of ADS-B OUT equipage is of more benefit to aircraft that are capable of using the ITP than those that are not (SA only). 


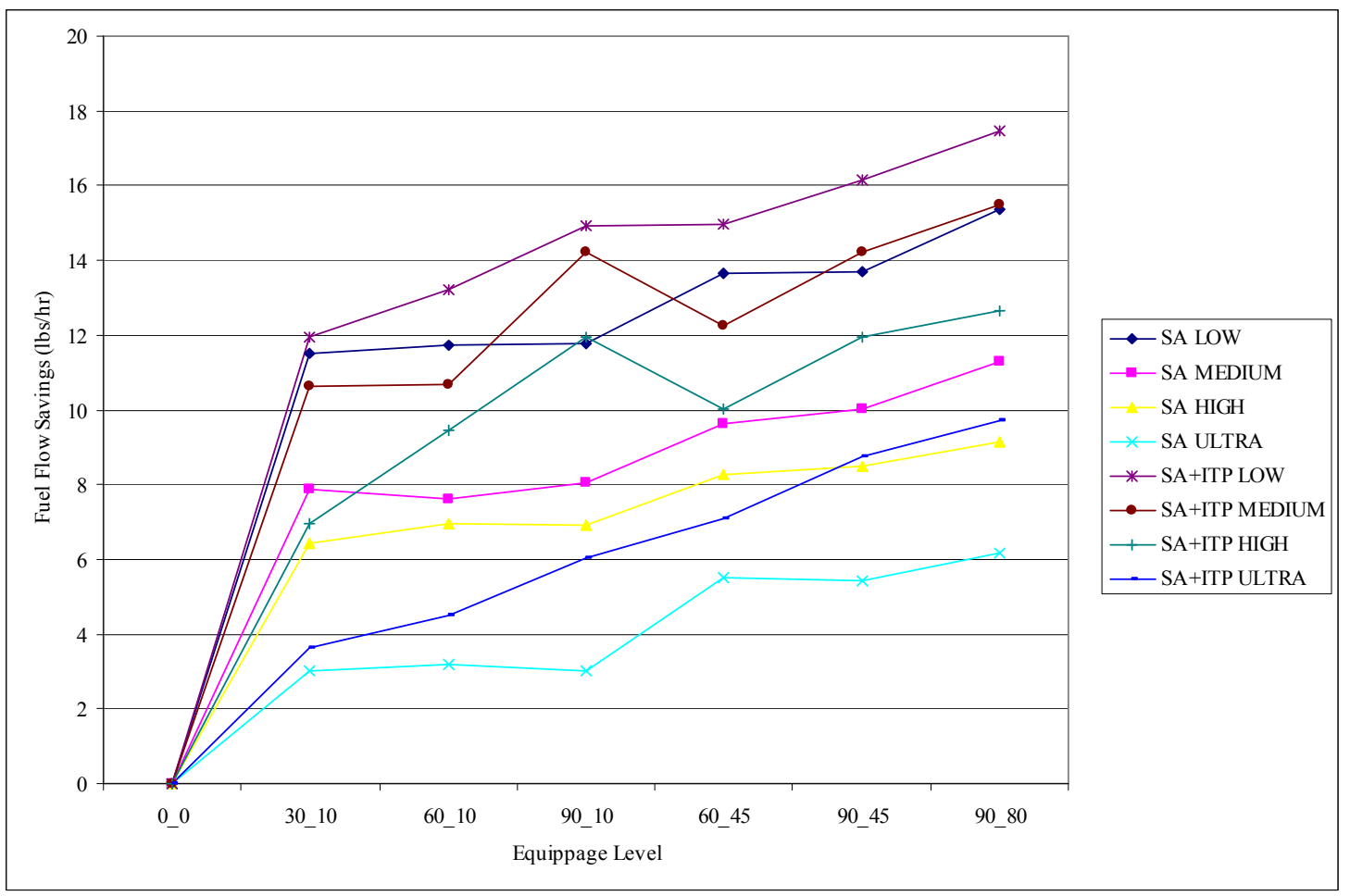

Figure 8. Average fuel flow savings from requested compromise entry scenarios (RM1)

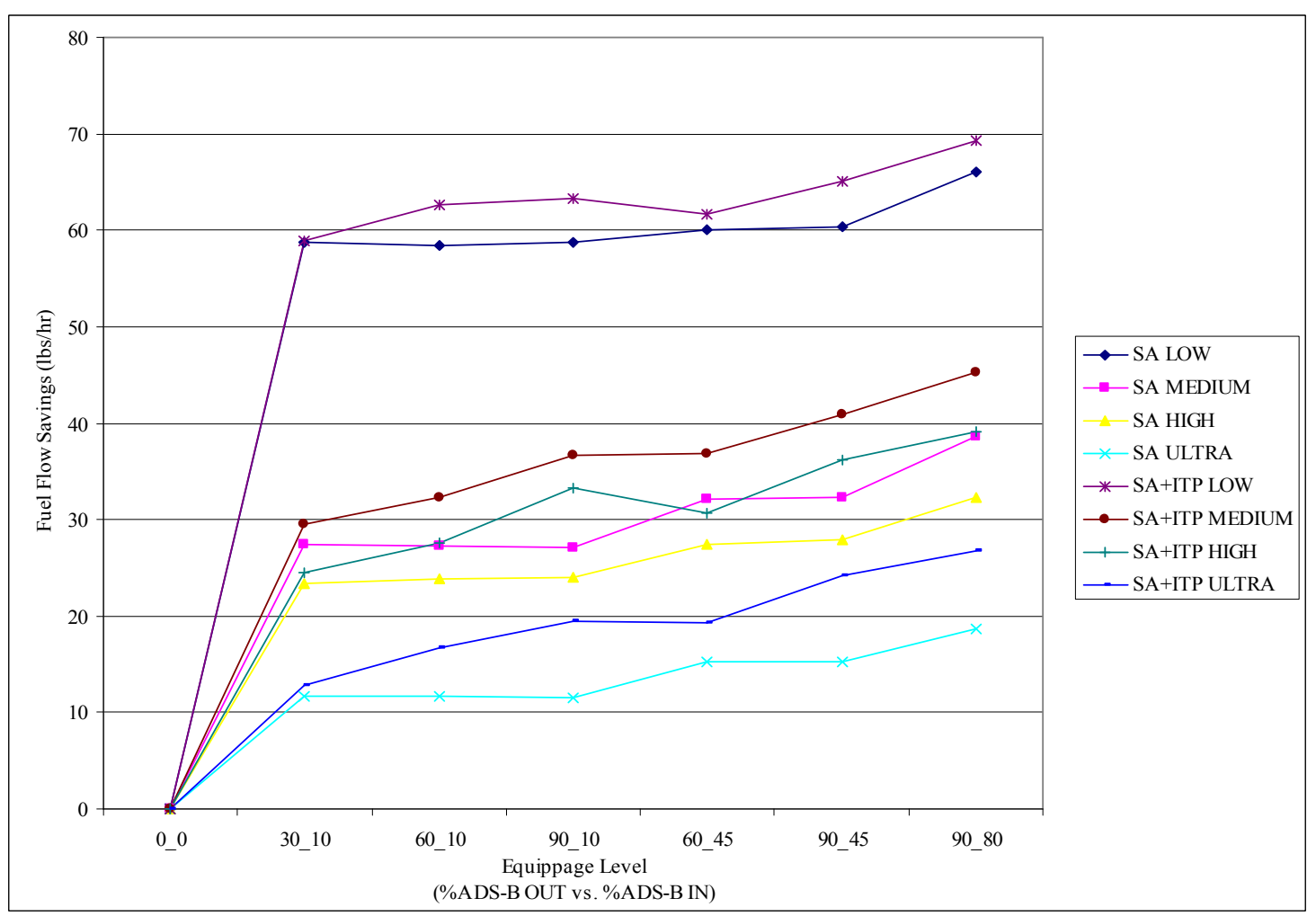

Figure 9. Average fuel flow savings from requested optimum entry scenarios (RM0)

American Institute of Aeronautics and Astronautics 
While the system-wide average is useful for investigating large-scale trends and effects, it is also useful to examine the results at an individual aircraft level. By considering the effects on the distribution of savings per aircraft a more detailed and accurate picture of the effects can be found. Figure 10 and Figure 11 show the distribution of the fuel savings (relative to the baseline) for all aircraft that were in the medium density, 90_80 equipage level, and could be equipped with both SA + ITP scenarios. The first series in each figure represents the savings or penalty that aircraft not equipped with ADS-B IN experienced. The second series shows the fuel savings experienced by those aircraft equipped with ADS-B IN.

Under RM1 and RM0 request methods less than $10 \%$ of non-ADS-B IN equipped aircraft had a fuel savings/penalty of more than $\pm 10 \mathrm{lbs} / \mathrm{hr}$. By comparison, ADS-B IN equipped aircraft in the RM1 and RM0 request methods experienced fuel savings greater then $+10 \mathrm{lbs} / \mathrm{hr}$ around $30 \%$ and $55 \%$ of the time, respectively. These ADS-B IN equipped aircraft were nearly all ( $>99.5 \%$ ) distributed with positive fuel savings only (i.e., no penalties). This shows that with the combination of SA and ITP the probability of ADS-B IN equipped aircraft saving fuel over the baseline is increased compared to aircraft with no ADS-B IN equipment. An important point is that non-ADS-B IN equipped aircraft are evenly distributed around a savings of $0 \mathrm{lbs} / \mathrm{hr}$. The increased maneuvering of ADS-B IN equipped aircraft does not cost non-ADS-B IN aircraft additional fuel. It also shows that the distribution is more favorable for ADS-B IN equipped aircraft with the RM0 entry requests than with the RM1 entry requests.

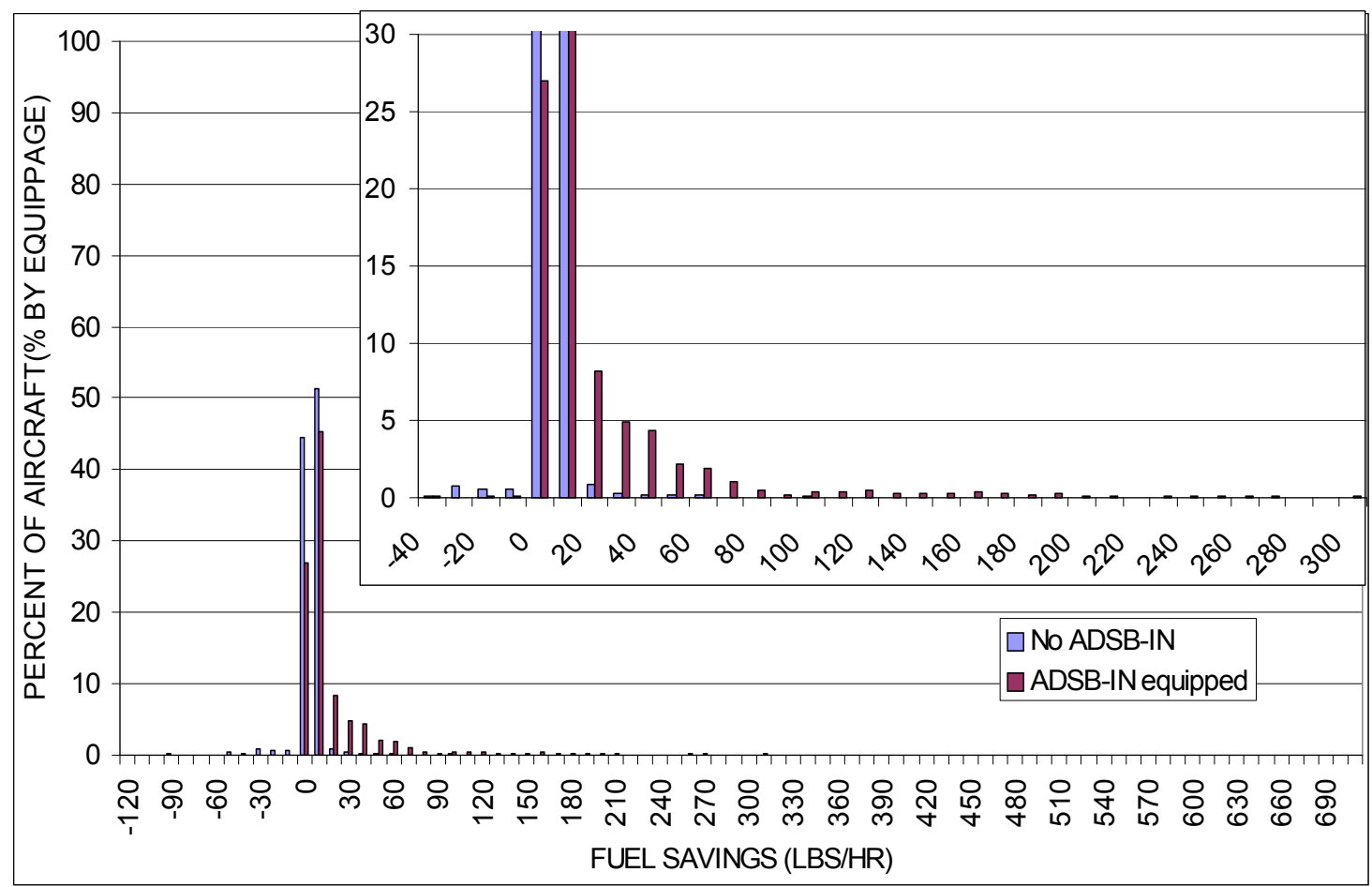

Figure 10. Fuel savings for all aircraft in Medium Density, 90_80 equipage, SA+ITP, requested compromise entry scenarios (RM1) 


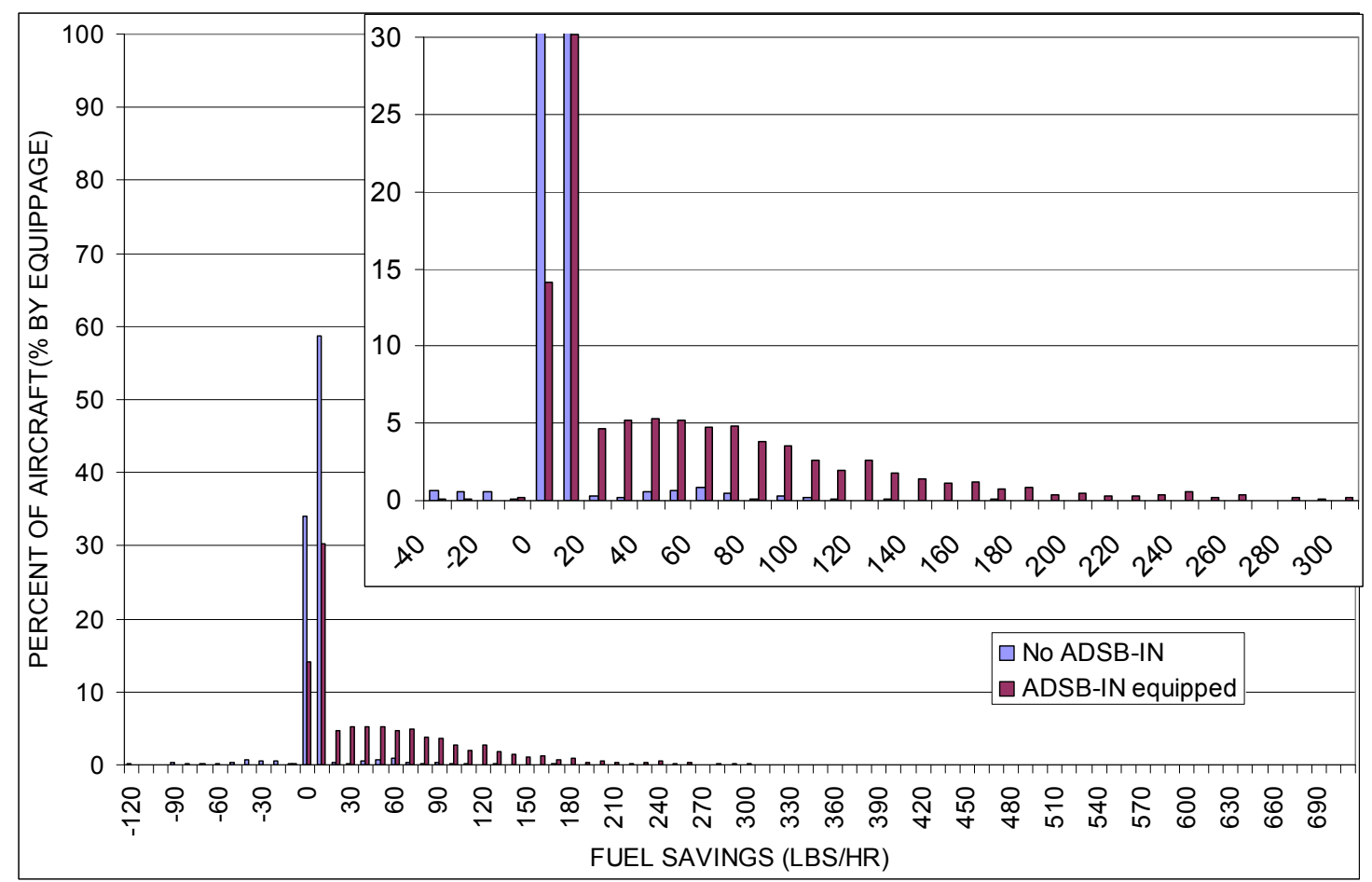

Figure 11. Fuel savings for all aircraft in Medium Density, 90_80 equipage, SA+ITP, requested optimum entry scenarios (RM0)

\section{Conclusion}

This experiment looked at the effects that the use of ADS-B IN and ADS-B IN plus the ITP had on the NATOTS. The effects were examined across multiple ADS-B equipage environments, traffic densities, and track entry altitude request methods. The results showed that the benefits of ADS-B increase with the percent of aircraft in the system equipped with ADS-B. The influence of increased levels of ADS-B IN on system improvements was shown to be larger than the influence from increased levels of ADS-B OUT (when looking at things from a system perspective). The effect of adding the increased flexibility in altitude change requests of the ITP also increased the overall system operational benefits compared to the addition of an ADS-B IN display alone. As the traffic density increased, the capability of ITP to allow aircraft to maneuver through altitudes at which current separation did not exist became an even more useful tool. The request method showed that there were more opportunities for aircraft to make improvements to their flight profile under the RM0 request method than under the RM1 request method. This was primarily due to the fact that the baseline conditions for the RM0 method were not as fuel efficient as the RM1 method baseline, providing for the improved savings on flights.

While not a focus of this experiment, there are other aspects to the NATOTS operation that could provide additional efficiency enhancements. This experiment indicates that there is a link between the efficiency of the requested altitude and track loading to the overall efficiency of the track system. If altitude selection and track loading could be optimized, then the efficiency of the system could be improved. Another source of large efficiency in the system could be if the separation standards were reduced, allowing for more aircraft to be located at their requested and optimum altitudes. This is the key feature of the ITP, that it helps aircraft find a way to reach their optimum altitude. Both the situation awareness aspects of an ADS-B IN display and the In-Trail Procedure would provide benefit if implemented in the NATOTS. The benefits provided may not justify the entire cost of the airframe implementation, but they could provide a strong contribution to a suite of ADS-B IN applications. 


\section{References}

1 Air Services Australia: www.airservicesaustralia.com/pilotcentre/projects/adsb/default.asp

2 Federal Aviation Administration:

www.faa.gov/about/office org/headquarters offices/ato/service units/enroute/surveillance broadcast/

3 Eurocontrol: www.eurocontrol.int/cascade/public/subsite_homepage/homepage.html

4 North Atlantic Systems Planning Group, Application of Separation Minima (North Atlantic Region) v1.0, ICAO European and North Atlantic Office, 29 September 2005

RTCA, Minimum Operational Performance Standards for $1090 \mathrm{MHz}$ Automatic Dependent Surveillance - Broadcast (ADS-B) and Traffic Information Services Broadcast (TIS-B), DO-260A, Washington, DC, April 10, 2003

6 RTCA, Minimum Aviation System Performance Standards for Automatic Dependent Surveillance Broadcast (ADS-B), DO-242A, Washington, DC, June 25, 2002 2008.

EUROCAE ED-159: Safety, Performance and Interoperability Requirements Document for ATSA-ITP Application, May

8 Bussink, F.J.L., Hoekstra, J., Heesbeen, W., Traffic Manager: A Flexible Desktop Simulation Tool Enabling Future ATM Research, 24th Digital Avionics Systems Conference, October 2005, Washington DC

9 Nuic, A., 2003, User Manual for the Base of Aircraft Data (BADA) - Revision 3.5, Eurocontrol Experimental Centre, Bretigny, France http://www.eurocontrol.int/eec/public/standard_page/ACE_bada.html

10 NOAA National Operational Model Archive \& Distribution System http://nomads.ncdc.noaa.gov/\#ncep_datasets

11 Rockwell Collins (ACAS-900): http://www.rockwellcollins.com/ecat/at/ACAS-900 2.html\#N27724

12 Chartrand, R.C., Bussink, F.J.L., Graff, T.J., and Jones, K.M., Operational Improvements from In-Trail Procedure in the North Atlantic Organized Track System, Draft NASA Technical Memorandum, 2008. 